\title{
SAÚDE BUCAL MATERNO-INFANTIL: UM ESTUDO DE REPRESENTAÇÕES SOCIAIS COM GESTANTES ${ }^{1}$ \\ PREGNANCY AND ORAL HEALTH: A SOCIAL REPRESENTATION STUDY SALUD ORAL MATERNO-INFANTIL: UN ESTUDIO DE REPRESENTACIONES SOCIALES CON LAS GESTANTES
}

\author{
Mirelle Finkler², Denise Maria Belliard Oleiniski , Flávia Regina Souza Ramos ${ }^{4}$
}

${ }^{1}$ Parte da Dissertação de Mestrado da primeira autora, intitulada "Representações sociais de gestantes sobre saúde bucal: uma referência para repensar a assistência odontológica materno-infantil”. Florianópolis(SC): Programa de Pós-Graduação em Odontologia/UFSC; 2003.

${ }^{2}$ Cirurgiã-dentista. Mestre em Odontologia - Área de concentração: Odontologia em Saúde Coletiva, pela UFSC. Professora Substituta do Departamento de Estomatologia/UFSC.

${ }^{3}$ Cirurgiã-dentista. Doutora em Odontologia. Professora Adjunto II do Departamento de Estomatologia/UFSC e do Programa de PósGraduação em Odontologia/UFSC. Orientadora.

${ }^{4}$ Enfermeira. Doutora em Filosofia de Enfermagem. Professora Adjunto IV do Departamento de Enfermagem/UFSC e do Programa de Pós-Graduação em Enfermagem/UFSC. Co-orientadora.

PALAVRAS-CHAVE:

Saúde bucal. Assistência odontológica. Gravidez. Mulheres grávidas.

\begin{abstract}
RESUMO: Trata-se de um estudo qualitativo, que objetivou compreender as representações sociais de gestantes sobre questões relacionadas à saúde bucal, por meio de entrevistas semi-estruturadas. A discussão dos resultados procura colaborar na instrumentalização dos profissionais da saúde ao proporcionar uma reflexão sobre a atual assistência odontológica prestada à gestante, a partir de achados tais como o entendimento do tratamento odontológico durante a gestação como um risco à saúde do feto e da influência da saúde bucal da gestante na saúde do filho. A aproximação entre gestantes, a odontologia e a equipe multiprofissional de saúde parece ser um desafio fundamental para o início de um ciclo de promoção de saúde bucal promissor, que exige, contudo, um repensar a formação de recursos humanos, com ênfase na dimensão educativa das práticas de saúde e no trabalho pré-natal interdisciplinar.
\end{abstract}

\section{KEYWORDS:}

Oral health. Dental care. Pregnancy. Pregnant women.
PALABRAS CLAVE:

Salud oral. Asistencia odontológica. Embarazo. Mujeres embarazadas.

\begin{abstract}
This is a qualitative study aimed to comprehend pregnant women's social representation about issues related to oral health. The data were collected through semi-structured interviews. The discussion intended to highlight topics that could contribute to enhance health workers' skills by providing reflections about the ongoing model for pregnant women dental care. To do so we outlined issues like the understanding of dental care during childbearing as harmful to the child and the influence of mother's oral health on the child's health. The beginning of a promising cycle of a better oral health promotion depends on a closer approach of pregnant women to dentists and the multi professional health team. Nevertheless it is necessary to rethink the human resources training emphasizing the educative dimension of health service and an interdisciplinary prenatal assistance.
\end{abstract}

RESUMEN: El presente estudio se trata de un abordaje cualitativo con el objetivo de comprender las representaciones sociales de las mujeres embarazadas y los problemas relacionados a su salud oral, a través de entrevistas semi-estructuradas. La discusión de los resultados busca colaborar en la instrumentalización de los profesionales de la salud al proporcionarse una reflexión en la actual asistencia odontológica brindada a la gestante, a partir de hallazgos como la representación del tratamiento durante el embarazo como un riesgo a la salud del feto, y la representación de la influencia de la salud oral de estas gestantes en la salud de su hijo. La aproximación entre gestantes, la odontología y el equipo muldisciplinario de salud, muestra ser un desafio fundamental para el inicio promisório de un ciclo de promoción para la salud oral. Exige, no obstante reformular conceptos sobre la formación de recursos humanos destacando la dimensión educativa de las prácticas de salud y el trabajo prenatal interdisciplinario.
Endereço:

Mirelle Finkler

Rua Jair Silva, 50, apto. 502

88020715 - Centro, Florianópolis, SC

E-mail:mirellefinkler@yahoo.com.br
Artigo original: Pesquisa

Recebido em: 15 de fevereiro de 2004

Aprovação final: 20 de junho de 2004 
JUSTIFICANDO E INTRODUZINDO O ESTUDO

Sabe-se que a assistência odontológica tem contribuído muito pouco para a melhoria das condições de saúde bucal das populações. A prática odontológica iatrogênica-mutiladora, dentistocêntrica, biologicista, individualista, centrada na técnica e pouco resolutiva, vigora desde sua origem. Como conseqüência, os índices epidemiológicos que refletem as condições de morbidade bucal, colocam o Brasil entre os países de piores condições de saúde bucal do mundo ${ }^{1}$.

Buscar a reversão desse modelo em favor da atenção integral à saúde, levando-se em consideração as necessidades da comunidade assistida de acordo com o seu perfil sócio-epidemiológico, deve ser o propósito de políticas públicas e da ação de profissionais do setor saúde. O ideal compartilhado é o de uma prática odontológica mais humana, saudável, eficiente e eficaz, que respeite democraticamente a dignidade dos indivíduos e dos grupos, dentro de seu contexto histórico, social e cultural e que consiga, dessa forma, promover a saúde geral através da saúde bucal, contribuindo para a melhoria da qualidade de vida na sociedade.

Sendo a saúde uma questão de natureza social, econômica, cultural, política e educacional, é necessário considerar que os trabalhos de promoção de saúde requerem, antes de tudo, um conhecimento aprofundado sobre a população com a qual se irá trabalhar. Mas poucas e recentes são as pesquisas em Odontologia que propiciam esse conhecimento aprofundado, considerando as pessoas e seus comportamentos a partir de sua inserção social, valores, crenças, enfim, de seu sistema de significação ${ }^{2}$. Esse tipo de estudo exige uma abordagem diferente da qual a Odontologia tradicionalmente tem trabalhado.

A metodologia de pesquisa qualitativa, enraizada na Antropologia Social, busca o relativismo e a singularidade dos grupos sociais. Tem por pressuposto que o real só pode ser apreendido a partir da ordem simbólica, uma vez que a realidade é uma construção social. Dentro desse contexto, a saúde e a doença possuem uma realidade independente de sua definição biomédica, pois são objetos de representações e tratamentos específicos em cada cultura. Independente do fenômeno biológico, a doença pode ser vista como um fenômeno social, que apesar de ser um acontecimento individual, mobiliza um conjunto de relações sociais ${ }^{3}$.

Pensando-se na família como um espaço pri- mário de relacionamento social, as mulheres e mães exercem uma influência especial, principalmente nas questões relacionadas à saúde, pois atuam como agentes produtoras e multiplicadoras de conhecimentos, informações e atitudes que visam à promoção da sua saúde e a de toda a sua família 4 .

O período da gestação é considerado um momento ímpar na vida da mulher, no qual ela demonstra estar bastante receptiva a informações relacionadas ao futuro filho, sendo por isso, a gestação, percebida como um momento privilegiado para o trabalho de educação em saúde.

Mas para que as mães possam efetivamente desempenhar seus papéis de promotoras de saúde necessitam, primeiramente, serem pessoas saudáveis. Entretanto, a alta prevalência de doenças bucais em gestantes está bem documentada pela literatura odontológica $^{5-6}$. É necessário reconhecer a mulher como ser integral que é, não simples reprodutora, mas sujeito de sua saúde e de sua própria vida. Assim será capaz de gerar e manter vidas igualmente saudáveis.

O tratamento da saúde bucal das gestantes deve ser entendido como parte dos cuidados pré-natais necessários ${ }^{5}$, por considerar também aspectos biológicos e clínicos como a recente associação entre doença periodontal em gestantes e nascimentos pré-termos e de baixo peso $^{7}$ e a relação positiva entre a experiência de cárie da mãe e a de seu filho ${ }^{8}$, desencadeada pela transmissibilidade bacteriana precoce $e^{5,7}$ e pelo compartilhamento de fatores culturais, comportamentais e sócio-econômicos do ambiente familiar.

Diversas pesquisas vêm sendo realizadas com gestantes no âmbito da Odontologia ${ }^{9-10}$ mas apesar dos esforços realizados no sentido de conhecê-las melhor em relação ao que sabem, pensam e fazem, como é a sua saúde bucal e qual a influência desta na saúde bucal de seus bebês, esse conhecimento tem sido obtido e analisado sob o prisma da corrente positivista, de forma que toda a realidade social e histórica, a comunicação inter-pessoal, o senso comum e as práticas sociais deixam de ser consideradas. ${ }^{4}$.

A importância de se compreender os saberes das gestantes relacionados à saúde bucal sob a perspectiva dos próprios sujeitos, tema que consubstanciou esta pesquisa, reside no fato de que é necessário compreender melhor para agir melhor. Essa compreensão possibilitaria a concepção de ações de educação em saúde mais efetivas e democráticas, por serem pensadas a partir da própria população a que se destinam, favorecendo a sua participação no controle do pro- 
cesso saúde-doença bucal ${ }^{11}$.

A Teoria das Representações Sociais de Moscovici, publicada em 1961, trata dos saberes sociais, considerando-os formas de conhecimento que circulam na sociedade, que são parte da cultura erudita, científica e popular, que se misturam, se retroalimentam mutuamente e se apresentam como recursos sociais para que uma comunidade possa dar sentido à sua realidade e conhecer o que está acontecendo. Enquanto instrumental teórico-prático, a Teoria das Representações Sociais possibilita a compreensão do desenvolvimento dos seres humanos e das sociedades. Constitui-se em uma perspectiva para se poder "ler" os mais diversos fenômenos e objetos do mundo soci$\mathrm{al}^{12}$. Pela concordância com sua visão de mundo, seus valores e crenças e por ser adequada à explicação do senso comum, foi selecionada como marco teórico, proporcionando direção a esta pesquisa e fundamentando a discussão de seus resultados.

Por acreditar na importância da promoção da saúde materno-infantil, considerando a repercussão positiva que traria em longo prazo para toda a população; por acreditar também na necessidade de se estudar os saberes das gestantes como construções sociais contextualizadas; e por encontrar na Teoria das Representações Sociais um referencial teórico que proporciona valor e significado a esta busca, o presente estudo foi desenvolvido, possuindo, entre outros*, os seguintes objetivos: compreender as representações sociais de gestantes sobre a saúde bucal do bebê; sobre a influência da sua saúde bucal na saúde de seu futuro filho; e sobre o seu papel de promotora de saúde bucal para o seu futuro filho.

\section{METODOLOGIA}

Considerando-se os aspectos éticos que envolvem as pesquisas com seres humanos, o projeto da presente pesquisa foi avaliado e aprovado pelo Comitê de Ética em Pesquisa com Seres Humanos da UFSC, sendo que a concordância das gestantes em participar da pesquisa e a permissão para a sua realização nas instituições selecionadas foram obtidas através de Termos de Consentimento Livre Esclarecido.

As gestantes participantes foram encontradas através de dois locais de serviços de saúde pré-natais em Florianópolis, um público e outro privado, conseguindo-se, dessa forma, incluir no estudo gestantes de diferentes classes sociais, constituintes do senso comum.

$\mathrm{O}$ método escolhido para a coleta de dados foi o da entrevista semi-estruturada. Para garantir o rigor metodológico e a conseqüente qualidade da pesquisa, o instrumento empregado foi submetido à avaliação de dois especialistas e, posteriormente, foi testado com uma gestante. Procurou-se alcançar o máximo de fidedignidade possível, através do uso de um gravador eletrônico em todas as entrevistas e pela sua transcrição imediata, realizada pela própria pesquisadora.

Sendo que "a amostragem qualitativa necessita de um número suficiente de sujeitos para permitir certa reincidência de informações"13:102, ao final da décimasegunda entrevista, o critério de saturação foi considerado satisfeito, perfazendo, o material coletado, o total de 12 entrevistas.

A análise das falas transcritas foi realizada através dos processos de ordenação dos dados, categorização inicial, reordenação e análise final ${ }^{13}$, resultando nas categorias "gestação \& Odontologia" e "a saúde do futuro filho", as quais são integradamente apresentadas e discutidas a seguir.

\section{AS REPRESENTAÇÕES SOCIAIS DAS GESTANTES}

\section{Dizem que...}

Existe uma crença muito forte, constatada também por diversos outros estudos e autores que contra-indica o tratamento odontológico durante a gestação. Esta crença compreende o tratamento odontológico durante a gestação como sendo um risco importante à saúde e até mesmo à vida do feto em desenvolvimento.

Como conseqüência, no momento em que a saúde da mulher se torna ainda mais importante por dela depender também a saúde e a vida de outro ser ${ }^{2}$, as gestantes não buscam tratamento odontológico ${ }^{6,14}$, chegando a interrompê-lo e abandoná-lo por conta própria ao saberem estar grávidas.

As justificativas apontadas pelas gestantes entrevistadas para a não procura pelo tratamento odontológico durante a gestação incluíram dificuldades financeiras, o desconforto durante o atendimento odontológico pela posição quase deitada da cadeira e

* A pesquisa original compreendia outros objetivos mais. Neste artigo são apresentados apenas os objetivos relacionados a duas das categorias de análise resultantes da pesquisa, as quais compõem o tema deste relato.

Texto Contexto Enferm 2004 Jul-Set; 13(3):360-8. 
pelos odores dos produtos utilizados, o medo de se sentir mal durante o atendimento ou de sentir dor num momento em que algumas mulheres se consideram mais sensíveis. Mas é principalmente o medo de que alguma coisa no tratamento odontológico venha a prejudicar o bebê, que torna este tipo de atendimento durante a gestação uma idéia quase inconcebível para algumas pessoas.

Este medo foi relacionado, principalmente, ao malefício em potencial de produtos químicos, cujo uso, as gestantes demonstraram saber muito bem, deve ser evitado. Considerando que remédios são produtos químicos e que seu uso deve ser limitado às indicações médicas, as gestantes descartam a possibilidade de utilizarem anestesia no atendimento odontológico e portanto, de realizá-lo. As gestantes parecem superestimar o risco de teratogenicidade para o feto, resultante dos procedimentos e/ou de drogas usadas nos tratamentos médico e odontológico ${ }^{15}$.

O conteúdo das falas sugeriu que as gestantes aceitam passivamente, inquestionavelmente, a "necessidade" de esperar o nascimento do bebê para "poder" retomar o tratamento. Nem mesmo a dor, apontada pelas entrevistadas como uma importante razão para a busca do atendimento odontológico, às vezes supera o medo e a resistência ao tratamento durante a gestação. Tal observação vem ao encontro das conclusões de um estudo a respeito das questões de gênero relacionadas à saúde bucal: "A carga social de gênero que se agrega à maternidade implica num enfrentar problemas de saúde, inclusive dores de dente, de forma solitária, uma vez que a busca de ajuda profissional pode significar para as gestantes, dentro do seu universo de conhecimentos construídos, um risco à saúde do bebê, risco este que não é socialmente permitido correr"'16:136.

O cumprimento "à risca" da recomendação médica enfatizada (não tomar remédios), associado à ausência do dentista no pré-natal ${ }^{4}$ e à falta de comunicação entre os profissionais das áreas da saúde, no sentido de encaminharem todas as gestantes para o tratamento odontológico ${ }^{17}$ colaboram para a manutenção deste componente da representação social que desaconselha a ida ao dentista. Porém, talvez seja o próprio receio dos dentistas em atender gestantes ${ }^{4,10,17}$, por meio de seu discurso científico, ${ }^{6,14}$, que tenha contribuído originalmente para a construção deste saber, mantendo-o presente.

Contudo, este receio não encontra fundamentos científicos, uma vez que a literatura assegura a pos- sibilidade de realizar o tratamento odontológico com gestantes sem maiores problemas, quando medidas de precaução são tomadas pelo profissional ${ }^{14-5,17}$.

Outro perigo percebido no tratamento odontológico durante a gestação também foi apontado pelas gestantes: a realização de tomadas radiográficas. Entretanto, o uso prudente da radiografia pode ser empregado durante a gestação, porque a radiação ionizante é teratogênica apenas em doses bem maiores do que a necessária para uma ou duas tomadas radiográficas que possibilitam um diagnóstico adequado de um problema odontológico específico. A indicação deve ser restrita apenas ao necessário e todas as precauções rotineiras devem ser tomadas ${ }^{4,15,17}$.

Outro componente da representação social compartilhada pelas gestantes e referenciada pela literatura $^{18}$, diz respeito a um prejuízo para a saúde bucal das mulheres, creditado ao estado fisiológico da gestação. Se o corpo da mulher como um todo se transforma por conta da fisiologia da gestação, é possível compreender porque as gestantes acreditam que seus dentes também sofram alterações.

A antiga e difundida crença de que ocorre uma descalcificação dos dentes da mulher durante a gravidez para suplementar minerais no crescimento do feto, não tem suporte científico ${ }^{7,19}$. Os minerais que passam para o bebê através da placenta e do aleitamento materno provém de diferentes processos biológicos, tais como o aumento no consumo alimentar e na absorção gastrintestinal de minerais e o decréscimo na excreção e a mobilização de minerais a partir do reservatório materno, o esqueleto ${ }^{20}$. Desta forma, o feto se forma às expensas do cálcio ósseo e circulante e não do cálcio dentário 4 . Cabe aqui ressaltar as diferenças existentes (embriológicas, histológicas e fisiológicas) entre ossos e dentes, as quais as gestantes parecem desconhecer, o que fomenta a crença em questão.

Vale ainda esclarecer que não existe uma relação direta de causa-efeito entre a gravidez e cárie. O que ocorre de fato são mudanças hormonais que diminuem o pH do meio bucal e a capacidade tampão da saliva; possíveis mudanças na alimentação pelo aumento do consumo de alimentos açucarados nesse período e possíveis mudanças nos hábitos de higiene bucal, além da também possível presença freqüente de ácidos provenientes de vômitos. Juntos estes fatores favorecem a atividade da doença cárie ${ }^{7,17}$.

Também as mudanças hormonais durante a gestação que aumentam a resposta inflamatória dos 
tecidos gengivais, resultando em gengivite quando na presença de placa bacteriana $a^{6,18}$, acabam por justificar a gestação como sendo prejudicial à saúde bucal da mulher. O entendimento do sangramento gengival como algo normal durante a gestação tem sido considerado negativo ${ }^{14}$, à medida que as gestantes podem estar negligenciando a higienização bucal com esta justificativa.

\section{Orientação profissional, uma necessidade sentida}

As gestantes mostraram-se repletas de dúvidas com relação à saúde bucal e aos cuidados que esta demanda, especialmente no tocante a bebês. Esta reconhecida falta de conhecimentos é por elas justificada pelo pouco contato com os profissionais da área, especialmente durante a gestação, pela ausência de sua tarefa enquanto educador para a saúde e pelo próprio desinteresse das pessoas, que pode ser compreendido pela falta de estímulo social para a participação e crítica popular.

Os profissionais que mantêm um contato mais freqüente com as gestantes parecem não estar conscientes da importância da atenção odontológica no prénatal $^{4}$ e por isso deixam de contribuir, através de orientações e encaminhamentos, para com a saúde das mulheres e de seus filhos em desenvolvimento.

Pode-se assim verificar, como em outras pesquisas ${ }^{10,14}$, que as gestantes não têm sido orientadas sobre os cuidados com a própria saúde bucal durante a gestação, nem sobre a necessidade de procurar o tratamento odontológico neste período e, muito menos, a respeito da saúde bucal de bebês. O pré-natal que vem sendo realizado na prática, parece excluir a saúde bucal das gestantes. Ou terá sido a Odontologia que, de certo modo, se excluiu da saúde geral e, portanto, também da atenção pré-natal?

De qualquer modo, a ausência do cirurgiãodentista na equipe do pré-natal parece ser aceita. No corredor do ambulatório de tocoginecologia de um hospital público de Florianópolis, uma placa afixada à parede apresenta as normas e rotinas do ambulatório para o incentivo do aleitamento materno: "A equipe interdisciplinar (Enfermeiro, Psicóloga, Pediatra, Obstetra, Neonatologista, Nutricionista, Serviço Social) proporcionará discussões e reflexões através de encontros e grupos de gestantes, trabalhando as questões de aleitamento[...]". A ausência da participação do dentista e da Odontologia nesta equipe interdisciplinar, a despeito de toda a contribuição que têm a oferecer, desperdiça um importante momento de encontro precoce entre dentistas e gestantes, fecundo para a educação em saúde.

O discurso das gestantes revelou uma necessidade sentida de irem em busca de respostas e orientações profissionais. Confirmando as constatações de outros estudos ${ }^{2,45}$, todas as gestantes entrevistadas nesta pesquisa demonstraram o desejo de adquirir informações que venham em benefício da saúde de seus filhos.

Entretanto, como não vislumbram a hipótese de realizarem tratamento odontológico durante a gestação, as gestantes guardam suas dúvidas para depois do parto, não obtendo os benefícios do trabalho educativo pré-natal e perdendo a oportunidade de serem aconselhadas a realizar o tratamento de que necessitam antes do filho nascer. Tratamento este que, ao beneficiar a saúde da mulher grávida, beneficiaria também o desenvolvimento normal da gestação e a saúde dos bebês ${ }^{17}$.

\section{Cuidar dos meus dentes para poder cuidar dos do meu filho}

A gestante e o feto como uma unidade constitui parte da representação social da gestação que concebe o corpo e a saúde do binômio mãe/filho como indissociáveis. Esta representação perpassou o discurso de todas as entrevistadas, tendo sido ancorada de diferentes formas, as quais permitem uma aproximação da compreensão que as gestantes possuem sobre a relação da sua saúde bucal com a saúde de seus futuros filhos:

- por meio da alimentação das gestantes, pelo conhecimento que possuem e que é continuadamente reforçado, sobre a sua importância para o desenvolvimento saudável de seus bebês em formação;

- por meio de medicações, possuindo estas efeitos negativos ou positivos sobre a saúde dos filhos, como crêem as gestantes. Cabe aqui esclarecer que a suplementação de flúor pré-natal teve sua prescrição descontinuada ${ }^{7}$ por não ser recomendável a gestantes ${ }^{20}$. A compreensão da odontogênese fetal e dos mecanismos de ação do flúor demonstraram não haver evidência biológica para suportar algum benefício para o bebê através da suplementação para a mulher grávida ${ }^{20}$. Contudo, ainda hoje se encontram médicos e mesmo dentistas pres- 
crevendo flúor associado a complexos vitamínicos no período pré-natal ${ }^{4}$, o que endossa a necessidade do trabalho interdisciplinar, da troca de conhecimentos entre as diferentes áreas da saúde e da atualização dos conhecimentos;

- por meio de complicações na gestação decorrentes da falta de cuidados da gestante com a saúde bucal e através da transmissão de bactérias da boca da gestante para o feto. Pode-se perceber que apesar das gestantes desconhecerem os meios exatos pelos quais sua saúde bucal poderia interferir na gestação e na formação de seus bebês, imaginam que tais fatos poderiam ser possíveis, aproximando suas justificativas de uma realidade potencial: a doença periodontal favorecendo o nascimento de crianças pré-termo e de baixo peso ${ }^{21}$;

- por meio dos cuidados tomados pela gestante com a saúde bucal, apesar de não saberem explicar exatamente como esses cuidados beneficiariam diretamente a saúde bucal dos bebês, o que sugere a compreensão da saúde e da saúde bucal como indissociáveis, fato confirmado em outras categorias de análise realizadas na pesquisa original. A indissociabilidade entre o organismo da gestante e o do feto parece ser suficiente para justificar qualquer tipo de relação entre a saúde bucal de um e de outro.

Após o nascimento, a relação entre a saúde bucal da mãe e a saúde bucal do bebê, foi fundamentada de três diferentes maneiras:

- pelo relacionamento físico íntimo entre a mãe e o filho, ancorada no aleitamento materno que dá continuidade ao vínculo físico pré-natal entre a mãe e o bebê, e na transmissibilidade bacteriana. Esta percepção demonstra que algumas gestantes estão positivamente conscientes da possibilidade de transmissão de bactérias bucais entre as pessoas, especialmente da transmissão vertical (entre mães e filhos);

- pelos cuidados em comum, ou seja, a saúde bucal da gestante está relacionada à do filho, à medida que os cuidados que são tomados em virtude de um, também os são para o outro. É positivo constatar que as gestantes compartilham este entendimento, mas se faz necessário também ressaltar que os cuidados com a saúde bucal não dependem apenas da vontade dos indivíduos e de seus conhecimentos, mas é mediada pela realidade social em que vivem;

- pelos exemplos fornecidos pelas mães a seus filhos. Este elemento da representação, que foi o mais referenciado pelas gestantes, está de acordo com o estudo ${ }^{22}$ que constatou ser o comportamento das mães quanto aos seus próprios hábitos higiene bucal o principal fator influenciador na aquisição de hábitos por parte das crianças, mais do que o nível sócioeconômico das mães ou suas crenças a respeito da saúde bucal. O dito popular que afirma que "se educa pelo exemplo" justifica esta relação apreendida que em muito pode contribuir na promoção da saúde de gestantes e de seus futuros filhos.

A importância das gestantes compreenderem que existe uma relação entre a sua saúde bucal e a de seus filhos reside na motivação que esta compreensão lhes proporciona na direção de se cuidarem mais, para desta forma beneficiarem seus bebês. Ainda que alguns componentes da representação social apreendida não coincidam com a visão que a ciência apresenta, o entendimento da inter-relação aqui discutida é benéfica e desejável sob o ponto de vista da promoção de saúde, pensando-se na motivação das gestantes para o autocuidado e para a busca da assistência profissional, antes, durante e após a gestação.

\section{Amor de mãe: desejos e compromisso com a saúde do filho}

Todas as gestantes acreditavam que poderiam contribuir ativamente para a saúde bucal de seus filhos, sentindo-se verdadeiramente responsáveis por ela. O papel de mãe enquanto promotora de saúde, pareceu querer ser assumido com satisfação ${ }^{23}$ pelas entrevistadas. Elas demonstraram estar dispostas a fazer todo o necessário para que seus filhos sejam saudáveis, o que inclui o cuidado com a própria saúde, como sugeriu a fala de uma delas: Eu mesma vou ter que me cuidar muito mais ainda do que en cuidava agora, né? (G2).

Para algumas gestantes a responsabilização pela higiene bucal do futuro filho recebe uma conotação de obrigação, especialmente para as que relataram ter recebido pouca orientação de suas famílias para os cuidados com a saúde bucal.

As entrevistadas expressaram desejos no sentido de que seus filhos sejam saudáveis. Representando 
a saúde como a ausência de doença, filhos saudáveis significam filhos não doentes, livre de sofrimento.

A preocupação de evitar o sofrimento do filho esteve calcada em suas experiências e na representação da saúde bucal e do tratamento odontológico, assim como as atitudes que pretendiam tomar neste sentido.

A vontade de dar aos filhos o que as mães não puderam ter e a sensação de ao fazer para o filho estarem fazendo para si próprias, características tão peculiares do "ser mãe" também foram percebidas.

\section{Concebendo/apreendendo cuidados}

A educação dos filhos, desde cedo, para as práticas de saúde bucal como uma rotina necessária, incluindo entre elas, basicamente, a escovação e a ida regular ao dentista, permeou a representação social de todas as entrevistadas.

Apesar das gestantes considerarem que a busca pelo tratamento odontológico deve ser precoce, percebe-se que a maioria delas desconhece o momento consensualmente considerado ideal para o início do acompanhamento profissional, que seria ainda no prénatal, seguido de uma primeira consulta por ocasião da erupção dos dentes decíduos. Este desconhecimento está relacionado à representação do tratamento odontológico como sendo de caráter curativo, muito embora a decisão de procurar o dentista para a obtenção de esclarecimentos e orientações com relação à saúde dos filhos também tenha sido uma constante em seus relatos.

Outro conteúdo fortemente presente no discurso das gestantes, foi a necessidade de que os cuidados sejam realizados desde o início pelas próprias mães, através da higienização da boca do bebê e, posteriormente, através da escovação dental, considerada a principal prática de higiene bucal. Pode-se perceber a necessidade da higienização bucal bem difundida, o que vem ao encontro da recomendação profissional no sentido da prevenção precoce da cárie dental, inclusive da cárie rampante, uma forma aguda de manifestação da doença que ocorre devido à falta de higiene após mamadas demasiadamente prolongadas, especialmente as noturnas que ocorrem com a criança dormindo, quando o reflexo da deglutição e a salivação estão diminuídas ${ }^{7}$. Contudo, o uso do fio-dental nas crianças não foi em nenhum momento referenciado.

A restrição parcial de alimentos cariogênicos foi mencionada por algumas gestantes que pareceram estar conscientes da importância de se racionalizar o consumo do açúcar. O cuidado com a transmissi- bilidade de microorganismos entre mãe e filho também foi um cuidado citado, assim como a escolha de instrumentos apropriados para os cuidados com a saúde bucal de bebês e crianças, atentando para o fato das gestantes estarem cientes da existência de recursos especiais que colaboram para o desenvolvimento saudável de seus filhos.

\section{CONSIDERAÇÕES FINAIS}

O despreparo dos profissionais da Odontologia para lidar com gestantes acaba por reforçar o elemento da representação social que desaconselha o tratamento durante a gestação ${ }^{6,9,14,17}$. O receio dos profissionais, fortemente direcionado para as preocupações com a segurança do tratamento curativo ${ }^{4}$, pode estar contribuindo negativamente para a construção da representação social reconstruída neste estudo.

Emerge então, a necessidade de uma reflexão referente ao perfil do profissional que a Odontologia tem formado. A literatura aponta não somente para os aspectos específicos do tratamento de gestantes, minimizando os riscos superestimados também pelos profissionais e o seu conseqüente temor em atendêlas $^{9,14}$, mas especialmente, para a compreensão da gestante enquanto sujeito que requer o que de melhor a atenção odontológica tem a oferecer: a sua ação integral - educativa, preventiva e reabilitadora ${ }^{4}$.

Para reverter esta realidade prejudicial à saúde materno-infantil, percebe-se ser necessário um adequado trabalho de educação em saúde, para o qual os profissionais da Odontologia precisam estar melhor preparados, conscientes da determinação social do processo saúde-doença, do seu papel de educadores e comprometidos com a transformação da sociedade.

Além disto, o engajamento dos profissionais da equipe de pré-natal, bem como a inclusão do dentista na mesma e a integração, atualização e cooperação entre os membros dessa equipe, no intuito de um reforçar o trabalho do outro e de falarem todos a mesma linguagem quando na comunicação com as gestantes, são importantes medidas a serem implementadas. Acrescente-se a isso a necessidade de se priorizar o atendimento odontológico às gestantes, através de sua institucionalização, com consultas atreladas às do prénatal ${ }^{4}$.

As gestantes possuem uma motivação, em potencial, para cuidar da própria saúde bucal pensando nos filhos e para buscar informações sobre os cuidados que deverão ser tomados com a saúde bucal dos 
bebês. Faz-se necessário, então, colocar as gestantes em contato com a Odontologia durante o período prénatal, para que recebam toda a orientação profissional necessária e para que sejam encaminhadas ao tratamento preventivo-reabilitador, pois mulheres saudáveis e que saibam se cuidar efetivamente promoverão a saúde de seus filhos.

Essa etapa, fundamental para promoção de saúde será, no entanto, apenas o primeiro passo de uma longa caminhada. O maior desafio que se apresentará então, será manter a motivação das mães permanentemente viva após o nascimento dos bebês, em meio às dificuldades da vida cotidiana e dos cuidados diários com os filhos, para que cresçam com sua saúde assistida.

Neste sentido, a criação do vínculo dentista-gestante, no momento inicial é primordial, pois poderá ser substituído pelo vínculo dentista-mãe-bebê num segundo momento e posteriormente, dentista-criança, dentista-adulto/gestante, conformando um círculo de saúde que recomeça a cada nova geração, estendendo seus benefícios a todos.

Para esta perspectiva de vínculo, a interdisciplinariedade constitui-se exigência e instrumento potencial, uma vez que articula diferentes saberes e práticas, sem desconhecer suas especificidades, em torno de uma visão mais ampla e integral das necessidades e problemáticas de saúde e de formas de intervenção mais qualificadas, competentes e humanizadas.

Sem desconsiderar as dificuldades e limitações concretas dos serviços públicos de saúde, da formação de recursos humanos para a área, e da própria Odontologia, algumas sugestões são apresentadas a seguir, a partir dos resultados obtidos com esta investigação, no sentido de fornecer subsídios aos trabalhos de educação em saúde e de melhorar a assistência odontológica materno-infantil:

- atentar para o conteúdo e a forma dos discursos profissionais, influenciadores diretos de representações sociais;

- divulgar amplamente a importância do atendimento odontológico preventivo, assim como a época ideal para o início da assistência odontológica, ainda no período pré-natal;

- estimular e apoiar políticas públicas que desfavoreçam a oferta e o consumo da sacarose em prol de produtos mais saudáveis, trabalhando de forma multidisciplinar as questões culturais vinculadas ao açúcar;
- repensar e reestruturar a formação do cirurgião-dentista, enfatizando-se a educação problematizadora, centrada nas necessidades sentidas e baseada na troca dos saberes e de experiências entre profissionais e comunidade;

- modificar o discurso e a atuação profissional, reforçadores de parte da representação social que contra-indica o tratamento durante a gestação, preparando o acadêmico adequadamente e levando informações concretas e seguras aos cirurgiões-dentistas em exercício, pelos meios de comunicação e de atualização profissional;

- priorizar o atendimento nos serviços odontológicos, antes, durante e após o período gestacional, de todas as mulheres em idade fértil, conscientizando-as da necessidade do tratamento odontológico também durante a gestação;

- incluir a Odontologia na assistência pré-natal, investindo no trabalho educativo junto às gestantes e atrelando o atendimento odontológico preventivo-reabilitador às consultas do prénatal;

- promover o trabalho verdadeiramente interdisciplinar no pré-natal, favorecendo a troca de informações e a cooperação permanentes;

- favorecer o aprendizado do trabalho interdisciplinar ainda no período de graduação, entre os diferentes cursos da área da saúde, trabalhando a incorporação do conceito de indissociabilidade entre saúde geral e saúde bucal;

- reforçar o componente da representação social acerca da influência da saúde bucal da gestante/mãe na saúde do bebê, através da conscientização do papel do ambiente social e dos cuidados tomados em comum, estimulando o autocuidado por parte das gestantes e a sua procura por assistência odontológica e, portanto, estendendo benefícios às futuras crianças;

- manter o suporte assistencial odontológico após o parto, às mães e bebês, para que o vínculo anteriormente criado tenha continuidade e possa, inclusive através de representações sociais, ampliar seus efeitos positivos à sociedade.

Diante das representações sociais objetificadas e de sua discussão, espera-se ter colaborado para uma reflexão sobre a importância do trabalho verdadeira- 
mente interdisciplinar no pré-natal, capaz de melhorar os níveis de saúde da população materno-infantil.

\section{REFERÊNCIAS}

1 Oliveira AGRC, Arcieri RM, Unfer B, Costa ICC, Moraes E, Saliba O. Modelos assistenciais em saúde bucal no Brasil: tendências e perspectivas. Ação coletiva 1999 Jan-Mar; 2(1):914.

2 Menino RTM, Bijella VT. Necessidades de saúde bucal em gestantes dos núcleos de saúde de Bauru. Conhecimentos com relaçäo à própria saúde bucal. Rev Fac Odontol Bauru 1995 Jan-Dez; 3(1/4):5-16.

3 Víctora CG, Knauth DR, Hassen MNA. Pesquisa qualitativa em saúde. Porto Alegre: Tomo; 2000.

4 Costa ICC. Atenção odontológica à gestante na triangulação médico- dentista-paciente [tese]. Araçatuba(SP): Programa de Pós-Graduação em Odontologia Preventiva e Social/ Universidade Estadual Paulista "Júlio de Mesquita Filho"; 2000 .

5 Rosell FL, Montandon-Pompeu AA, Valsecki Junior A. Simplified periodontal record for pregnant women. Rev Saude Publica 1999 Apr; 33(2):157-62.

6 Narvai PC. Saúde bucal de gestantes: prevalência de apicopatias e outros problemas dentais no município de Cotia/ SP. RGO 1984 Jul-Set; 32(3):243-9.

7 Casamassimo PS. Maternal oral health. Dent Clin North Am 2001 Jul; 45(3):469-78.

8 Araújo FB, Figueiredo MC. Promoção de saúde em odontopediatria. In: Kriger L, editor. Promoção de saúde bucal. $2^{a}$ ed. São Paulo: Artes Médicas; 1999. p. 285-348.

9 Maeda FHI, Toledo LP, Pandolfi M. A visão das gestantes quanto às condutas odontológicas na cidade de Franca (SP). Rev Odontol Vitória 2001Jul-Dez; 3(2):8-14.

10 Santos-Pinto LD, Uema APA, Galassi MAS, Ciuff NJ. O que as gestantes conhecem sobre saúde bucal? J Bras Odontopediatr 2001 Set-Out; 4(20):429-34.

11 Wendhausen A. A construção da subjetividade nos serviços de saúde: da sujeição à autonomia solidária. Texto Contexto Enferm 2000 Ago-Dez; 9(3):54-73.
12 Guareschi P. Representações sociais: alguns comentários oportunos. In: Nascimento-Schulze CM, editor. Novas contribuições para a teorização e pesquisa em representação social. Florianópolis: UFSC; 1996. p. 9-36.

13 Minayo MCS. O desafio do conhecimento. $6^{a}$ ed. São Paulo: Hucitec; 1999.

14 Scavuzzi AIF, Rocha MCBS, Vianna MIP. Percepção sobre atenção odontológica na gravidez. J Bras Odontopediatr Odontol Bebê 1998 Out-Dez; 1(4):43-50.

15 Wasylko L, Matsui D, Dykxhoorn SM, Rieder MJ, Weinberg S. A review of common dental treatments during pregnancy: implications for patients and dental personnel. J Can Dent Assoc 1998 Jun; 64(6):434-9.

16 Silva ADM, Gomes AM. Saúde bucal de gestantes: uma abordagem de gênero. In: Anais do $2^{\circ}$ Congresso Mundial de Odontologia; 2001 Jul 10-13; Londrina, Brasil. Londrina: AONP; 2001. p.36.

17 Livingston HM, Dellinger TM, Holder R. Considerations in the management of the pregnant patient. Spec Care Dentist 1998 Sep-Oct; 18(5):183-8.

18 Scavuzzi AIF, Rocha MCBS, Vianna MIP. Influência da gestação na prevalência da cárie dentária e da doença periodontal. Rev Fac Odontol UFBA 1999 Jan-Jun; 18:1521.

19 Prentice A. Micronutrients and the bone mineral content of the mother, fetus and newborn. J Nutr 2003 May; 133(5 Suppl 2):1693S-9.

20 Silva MFA. Flúor sistêmico: aspectos básicos, toxicológicos e clínicos. In: Kriger L, editor. Promoção de saúde bucal. São Paulo: Artes Médicas; 1999. p.143-65.

21 Dasanayake AP. Poor periodontal health of the pregnant woman as a risk factor for low birth weight. Ann Periodontol 1998 Jul; 3(1):206-12.

22 Chen MS. Children's preventive dental behavior in relation to their mothers' socioeconomic status, health beliefs and dental behaviors. ASDCJ Dent Child 1986 Mar-Apr; 53(2):105-9.

23 Budó MLD. A mulher como cuidadora no contexto de uma comunidade rural de imigração italiana. Texto Contexto Enferm 1997 Jan-Abr; 6(1):181-91. 